\title{
Fórum sobre guarda compartilhada: uma interlocução entre universidade e sociedade
} Forum for joint custody: a dialogue between university and society

\section{Introdução}

O relato visa apresentar o Fórum sobre guarda compartilhada, uma atividade de extensão universitária desenvolvida pelo Programa de Formação em Direitos da Infância e da Juventude - Pró-Adolescente, em parceria com os integrantes da pesquisa Convivência familiar: dificuldades e impasses, ambos vinculados ao Instituto de Psicologia da Universidade do Estado do Rio de Janeiro (UERJ).

Tendo em vista que, em 13 de junho de 2008, foi sancionada a Lei $n .^{\circ} 11.698$, que regulamentou a aplicação da guarda compartilhada no território brasileiro, decidiu-se organizar um Fórum sobre o tema nos meses de junho e julho de 2008, objetivando promover esclarecimentos e uma profícua discussão sobre a guarda compartilhada e as justificativas para sua aplicação.

A proposta de realização do Fórum partiu da percepção sobre o desconhecimento acerca da guarda compartilhada evidenciado por pais e mães separados, entrevistados em pesquisa desenvolvida anteriormente ${ }^{1}$, bem como em investigação na qual foram realizados grupos de reflexão com genitores que haviam rompido a relação conjugal ${ }^{2}$. Os participantes das duas pesquisas trouxeram queixas quanto à determinação de guarda unilateral - comumente outorgada nos Juízos de Família -, além de dúvidas sobre o que seria a guarda compartilhada e suas possíveis vantagens. Os pais lamentavam a falta de informações a respeito do assunto, relatando a necessidade de esclarecimentos e debates acerca dessa modalidade de guarda. No decorrer das investigações foi observada, também, a demanda de ONGs - organizadas por genitores separados - pelo oferecimento de espaços coletivos de discussão sobre a temática. Dessa maneira, de posse do vasto material levantado nas
Leila Maria Torraca de Brito', Christine Vieira Pereira', Joyce Barros Pereira ${ }^{3}$

\section{Resumo}

Este trabalho tem como objetivo apresentar o Fórum sobre guarda compartilhada promovido pelo Programa Pró-Adolescente da Universidade do Estado do Rio de Janeiro. A atividade foi realizada após a promulgação da lei sobre a guarda compartilhada, visando propiciar maiores esclarecimentos e debates sobre a temática. No texto são narradas as etapas de planejamento e desenvolvimento do Fórum, os temas das palestras proferidas por docentes e discentes de pós-graduação e os assuntos discutidos no decorrer dos debates. Os participantes do evento aprovaram o formato do mesmo, sugerindo novas edições não só na universidade como em outras instituições.

Palavras-chaves: Guarda compartilhada; Extensão universitária; Psicologia jurídica

Área temática: Direitos Humanos e Justiça Linha da Extensão: Direitos individuais e coletivos
Professora Adjunta do Instituto de Psicologia da UERJ, coordenadora do Programe de extensão Pró-Adolescente.

E-mail: leilatorraca@ymail.com

2 Psicóloga, mestranda do Programa de Pós-graduação em Psicologia Social da UERJ, bolsista CAPES.

E-mail: tine_pereira@yahoo.com.br

${ }_{3}^{3}$ Bolsista de Iniciação Científica PIBIC/CNPq/UERJ, bolsista de extensão da UERJ de março de 2008 a julho de 2009.

E-mail: joyce.bpereira@yahoo.com.br 
pesquisas, inicialmente divulgado em diversas publicações sobre o tema, decidiu-se dar sequência ao trabalho, organizando um Fórum sobre guarda compartilhada, uma atividade de extensão universitária. Como explanam Almeida e Oliva3 "cabe à extensão abrir caminhos entre a comunidade acadêmica e a externa, possibilitando, a cada uma das partes, o enriquecimento necessário para o processo integrador de produção de conhecimentos".

\section{Metodologia}

O Fórum sobre guarda compartilhada foi realizado em quatro reuniões quinzenais de duas horas cada, com entrada franca, no horário da noite, em auditório da UERJ. Os encontros ocorreram nos dias 18 e 30 de junho, 16 e 30 de julho de 2008.

A divulgação para o Fórum foi feita por meio da mala direta do Pró-Adolescente, de pequenos cartazes afixados na universidade, por intermédio de páginas eletrônicas de organizações de pais e mães separados, da página do Instituto Brasileiro de Direito de Família (IBDFAM) e do site da UERJ. As inscrições para participação na atividade ocorreram por telefone e por e-mail; o número de inscritos chegou a cento e cinquenta, sendo que oitenta e sete pessoas compareceram ao citado Fórum. Dentre os participantes havia pais, mães, discentes de diversas áreas de conhecimento da UERJ e de outras universidades, profissionais das áreas de Psicologia, Serviço Social, Educação e Direito, sendo que alguns atuavam no Tribunal de Justiça do estado do Rio de Janeiro.

A organização e o desenvolvimento do evento foram efetuados por docentes, alunos e colaboradores que participavam tanto do Programa de extensão como da pesquisa, que reunia bolsistas de iniciação científica, bolsistas de extensão, além de alunos de mestrado e de doutorado do Programa de Pós-graduação em Psicologia Social da UERJ. No planejamento traçado com a equipe, foi decidido que cada encontro seria conduzido por dois ou três profissionais, integrantes da pesquisa, que explorariam seus temas de estudo. Optou-se pelo formato de pequenas palestras, por vezes com uso de data-show, seguidas de debates com o público presente. A responsabilidade de registro dos encontros do Fórum - escrito e em áudio - foi atribuída a dois bolsistas de extensão.
No primeiro dia do evento a coordenadora da atividade e uma aluna de mestrado apresentaram os objetivos do Fórum, bem como resultados de pesquisas realizadas com pais e mães separados. As diferenças entre a guarda unilateral e a guarda compartilhada também foram descritas, analisando-se argumentos comumente empregados contra e a favor dessa última modalidade de guarda.

Na segunda reunião do Fórum, conduzida por alunos de mestrado sob a supervisão da docente responsável pela atividade, foi priorizado o tema das alianças entre os filhos e um dos pais que, por vezes, se estabelecem como desdobramento de uma separação conjugal. Houve destaque para a análise da denominada síndrome de alienação parental, assunto em evidência naquele momento e que estava sendo pesquisado por uma das mestrandas.

No terceiro encontro, de responsabilidade de uma doutoranda e de duas mestrandas, foi divulgada a Lei $n^{\circ} 11.698$, de 2008, analisando-se as vantagens da guarda compartilhada a partir dos resultados de pesquisas realizadas com famílias que passaram por separação conjugal tanto no Brasil como em outros países.

A última reunião do Fórum foi conduzida por uma doutoranda e pelo coordenador executivo do Pró-Adolescente, tendo como tema "escola e pais separados: uma parceria possível”, assunto que fora pesquisado pela discente em sua dissertação de mestrado ${ }^{4}$, seguindo sugestão de pais que participaram de pesquisas anteriores.

\section{Desenvolvimento}

Na reunião de abertura do Fórum, ao apresentar resultados de pesquisas empreendidas com pais e mães separados, informou-se que em uma primeira etapa os dados foram coletados por meio de entrevistas individuais realizadas com 49 pessoas, residentes em municípios do estado do Rio de Janeiro. Em uma segunda pesquisa, obtiveram-se os dados por intermédio de dois grupos de reflexão, realizados com 16 pais e mães separados, de classe média, residentes na cidade do Rio de Janeiro. Ainda naquela pesquisa, foram realizadas, posteriormente, 30 entrevistas com filhos de pais separados, com idades entre 21 e 29 anos.

A reunião do material colhido ao longo dessas investigações apontou, conforme mostram estatísticas oficiais ${ }^{5}$, o grande número de guardas 
atribuídas às mães, cabendo aos pais a visitação dos filhos, geralmente em finais de semana alternados. Notou-se, entretanto, forte descontentamento dos pais que não permaneciam com a guarda dos filhos no que diz respeito às possibilidades de contato e de participação na educação dos mesmos, devido ao afastamento que se impunha, por vezes, no modelo de guarda unilateral. Muitos consideravam que a justiça deveria reafirmar a co-responsabilidade entre os pais no que diz respeito aos cuidados dos filhos, lembrando que o rompimento que houve foi em relação à conjugalidade e não à parentalidade.

De maneira semelhante, diversos filhos lamentavam a ausência ou o afastamento que se estabeleceu com aquele pai que não detinha a guarda. Muitos compreendiam que as mães guardiãs desempenhavam bem suas atribuições, que, aliás, eram muitas, entretanto, ressaltavam que sentiam falta de uma maior aproximação com o pai e com a família deste. Dessa forma, ao se relacionar os resultados obtidos ao longo dessas pesquisas, foi possível apontar dificuldades decorrentes do emprego da guarda unilateral que atingiam pais, mães e filhos.

Cabe ressaltar que, atualmente, a Constituição Federal Brasileira estabelece a convivência familiar como um direito da criança, que deve ser assegurado pela família, pela sociedade e pelo Estado. Nesse sentido, alguns participantes do Fórum fizeram questão de lembrar que a lei sobre a guarda compartilhada não surgiu de repente, mas que traz o reflexo de mudanças sofridas pelas organizações familiares.

O segundo encontro teve início com o tema das fortes alianças que podem ser estabelecidas entre o guardião e os filhos, ou um deles, após a separação e o quanto a guarda unilateral pode contribuir para que haja tentativa de exclusão de um dos pais da vida da criança. Discorreu-se também sobre a denominada síndrome de alienação parental (SAP), tema novo e de grande interesse dos participantes por haver, na época, proposta para projeto de lei sobre o assunto. Segundo Gardner ${ }^{6}$, psiquiatra norte-americano que cunhou o termo, a síndrome de alienação parental seria um distúrbio infantil que poderia ocorrer em crianças expostas a desgastantes litígios entre os pais, situação em que um dos genitores induziria a criança a rejeitar o outro pai. Como há diversas controvérsias a respeito das ideias desse autor questionou-se, junto aos participantes do Fórum, se a SAP seria uma patologia ou efeito de práticas e de discursos engendrados na sociedade. Alertou-se para o fato de que, durante muito tempo, se estabeleceu uma primazia materna no cuidado infantil facilitando, dessa forma, o forte apego de algumas mães com seus filhos e a promoção do distanciamento dos pais ${ }^{7}$. Quanto ao tema, cabe esclarecer que a Lei Federal n. 12.318, que dispõe sobre a alienação parental, foi promulgada em agosto de 2010.

No terceiro encontro, notou-se a demanda dos participantes para a discussão da lei $n^{\circ} 11.698$, de 2008 , a qual dispõe no $\S 2^{\circ}$ do artigo 1.584 que: "quando não houver acordo entre a mãe e o pai quanto à guarda do filho, será aplicada, sempre que possível, a guarda compartilhada". Foi comum ouvir dos participantes a seguinte frase: "pois é, alguns dizem que a teoria é linda, mas a prática (...). Como fica a guarda compartilhada quando há litígio?". Quanto a esta indagação pode-se recordar que, ao se pensar em eleger o bom relacionamento entre os pais da criança como critério para o estabelecimento da guarda compartilhada, se estaria unificando o que é do âmbito da conjugalidade ao da parentalidade, contextos que, atualmente, se percebe a importância de serem dissociados após o rompimento conjugal. Entende-se, contudo, como ressaltou um dos participantes do Fórum, que a lei da guarda compartilhada não irá resolver todas as situações, mas funcionará como um norte, um suporte social para que seja mantida a convivência entre pais e filhos que não residem juntos.

No quarto encontro do Fórum, foram apresentados resultados de uma pesquisa empreendida junto a onze colégios particulares situados em bairros da zona norte da cidade do Rio de Janeiro. $\mathrm{Na}$ investigação realizada por $\mathrm{Cardoso}^{4}$, durante seu curso de mestrado junto ao Programa de Pós-graduação em Psicologia Social da UERJ, a aluna teve como intuito observar como vem ocorrendo a relação pais-escola, sobretudo com pais separados que não convivem diariamente com os filhos e que desejam acompanhar o desenvolvimento escolar desses. Na pesquisa, a discente percebeu a dificuldade de alguns professores e orientadores educacionais que entrevistou em lidar com as novas configurações familiares. Muitos profissionais responderam que a comunicação da escola com os responsáveis se dava primordialmente por meio das agendas dos alunos, nas quais eram anexados todos os informes e avisos. Nesses casos, pode-se 
pensar na dificuldade dos pais que não residem com os filhos em obter informações a respeito do cotidiano escolar dos mesmos quando o guardião da criança opta por não fornecer esclarecimentos.

As festividades na escola também foram lembradas pelas professoras entrevistadas como momentos de muita tensão para algumas crianças, especialmente comemorações do Dia das Mães e do Dia dos Pais. Nesses eventos, alguns alunos perguntavam se poderiam fazer mais de um presente, pois queriam oferecer a lembrança também para o padrasto, por exemplo. Talvez por esse motivo, Cardoso ${ }^{4}$ encontrou escolas que mudaram a postura em relação a essas festividades, optando por não realizar comemorações ou por comemorar o Dia da Família. Nesse encontro do Fórum foi apresentada, ainda, a Lei 3.849 de 2006, do Distrito Federal, que determina aos estabelecimentos de ensino da rede pública e da rede privada, o envio de informações escolares tanto ao pai quanto à mãe das crianças, para que estes possam acompanhar a vida escolar dos filhos. Cabe informar, ainda, que a partir de 6 de agosto de 2009 a Lei Federal n¹2.013, reconhece esta como uma obrigação de todas as instituições de ensino nacionais.

Para aqueles que participaram do Fórum, as escolas deveriam se empenhar em promover entrosamento com os pais, principalmente com os que não habitam com os filhos, o que poderia ocorrer por meio de eventos.

\section{Conclusões}

$\mathrm{Na}$ atividade realizada, buscou-se colocar em prática a integração entre ensino, pesquisa e extensão, quando os alunos de pós-graduação puderam não só proferir palestras sobre seus temas de estudo, como divulgar os resultados de pesquisas realizadas. Dessa maneira, o Fórum sobre guarda compartilhada foi um recurso facilitador para a divulgação do conhecimento à sociedade, promovendo a interlocução da universidade com outros segmentos sociais.

A possibilidade de diálogo entre diferentes grupos da sociedade, que ocorreu ao longo do Fórum, foi compreendida pelos participantes como uma iniciativa importante, fundamental por parte da universidade e que deveria se repetir em outros contextos institucionais como, por exemplo, nas escolas e nos Fóruns de Justiça.

\section{Referências}

1. BRITO, Leila Maria Torraca. Impasses na condição da guarda e da visitação - o palco da discórdia. IN: PEREIRA, R. C. (Coord.). Família e Cidadania. O Novo CCB e a Vacatio Legis. Anais do III Congresso Brasileiro de Direito de Família. Belo Horizonte: IBDFAM/Del Rey, 2002. p.433-448.

2. BRITO, Leila Maria Torraca. Alianças desfeitas, ninhos refeitos: mudanças na família pós-divórcio. In: , L. (Org.). Famílias e separações: perspectivas da psicologia jurídica. Rio de Janeiro: EdUERJ, 2008. p.17-48.

3. ALMEIDA, Alecsandra e OLIVA, Vagner José. A extensão universitária como atividade fim. Interagir: pensando a extensão. Rio de Janeiro, n.5, p.27-36, jan./jun.2004.

4. CARDOSO, Andréia Ribeiro. Escola e pais separados: uma parceria possível. Curitiba: Juruá, 2009, $122 \mathrm{p}$.

5. INSTITUTO BRASILEIRO DE GEOGRAFIA (IBGE). Estatísticas do Registro Civil. Rio de Janeiro: IBGE, v.35, p.1-170, 2008.

6. GARDNER, Richard. The parental alienation syndrome: a guide for mental health and legal professionals. Cresskill, New Jersey: Creative Therapeutics, Inc. 1998, 448 p.

7. SOUSA, Analícia Martins. Síndrome da Alienação Parental: um novo tema nos juízos de família. São Paulo: Cortez, 2010, 222 p.

\section{Abstract}

This article aims to present the Forum for joint custody sponsored by the Pró-Adolescente Program developed by the State University of Rio de Janeiro. The activity was carried out after the law about joint custody was enacted, in order to provide further clarifications and discuss the matter. The article features the Forum's planning and development stages, the themes of the lectures given by professors and graduate students and the matters debated. The participants in the event approved its format, and made suggestions for new editions inside and outside the university.

Keywords: Joint custody; University extension; Forensic psychology 